\title{
Localization of Vascular Endothelial Growth Factor and Its Receptors in Digestive Endocrine Tumors: Correlation With Microvessel Density and Clinicopathologic Features
}

\author{
STEFANO LA ROSA, MD, SILVIA UCCELLA, MD, \\ GIOVANNA FINZI, BSC, LUCA ALBARELLO, MD, FAUSTO SESSA, MD, \\ AND CARLO CAPELLA, MD
}

\begin{abstract}
Angiogenesis, a process related to tumor growth and malignancy, is stimulated by several growth factors. Among these is vascular endothelial growth factor (VEGF), which acts on endothelial cells by binding with 2 specific receptors, VEGFR1 and VEGFR2. Recent studies have demonstrated that VEGF expression is correlated with microvessel density (MVD) and tumor progression. Digestive endocrine tumors are heterogeneous neoplasms exhibiting variable biological aggressiveness and behavior that often are not predictable on morphologic grounds alone. The aims of this study were to evaluate the expression of VEGF, VEGFR1, and VEGFR2 in digestive endocrine tumors and to examine its correlation with MVD and malignancy. A total of 84 specimens from endocrine neoplasms and normal gut and pancreatic tissue were immunohistochemically studied using specific antibodies directed against VEGF, VEGFR1, VEGFR2, endothelial antigens, and gastroenteropancreatic hormones. Ultrastructural immunocytochemistry was performed to identify the cellular localization of VEGF and the VEGFRs. In normal tissues, VEGF immunoreactivity was detected in G cells and PP cells. Ultrastructur-
\end{abstract}

Angiogenesis, the physiologic formation of new blood vessels, is essential for tissue development, reproduction, and wound healing. Unregulated angiogenesis also plays an important role in the pathogenesis of proliferative retinopathy, rheumatoid arthritis, and cancer. ${ }^{1}$ In particular, it has been demonstrated that once a tumor reaches about 1 to $2 \mathrm{~mm}^{3}$ in size, its growth depends strictly on angiogenesis, which also contributes to the metastatic process, facilitating the shedding of tumor cells into blood vessels. ${ }^{2}$ Angiogenesis is generally evaluated by microvessel counting. The number of microvessels has been related to metastatic dissemination, tumor aggressiveness, and patient survival in several human tumors, including melanocytic, breast, lung, prostate, cervical, head and neck, testis, ovarian, gastric, pancreatic, and brain malignancies. ${ }^{3-5}$

From the Department of Pathology, Ospedale di Circolo, Varese, Italy and the Department of Clinical and Biological Sciences, University of Insubria, Varese, Italy. Accepted for publication September 18, 2002.

Supported in part by a grant from the University of Insubria.

Address correspondence and reprint requests to Professor Carlo Capella, Servizio di Anatomia Patologica, Ospedale di Circolo, Viale Borri 57, I-21100 Varese, Italy.

Copyright 2003, Elsevier Science (USA). All rights reserved.

0046-8177/03/3401-0004\$30.00/0

doi:10.1053/hupa.2003.56 ally, VEGF was localized within secretory granules. The VEGFRs were not significantly expressed by normal endocrine cells. VEGF-immunoreactive (IR) cells were detected in $\mathbf{4 0}$ of $\mathbf{8 3}$ tumors, mainly G cell and enterochromaffin cell neoplasms. VEGFR1-IR cells were found in 44 of 82 tumors, and VEGFR2-IR cells were found in 55 of 82 tumors, with no predilection for any specific tumor type. The expression of VEGF and its receptors did not correlate with MVD or malignancy. These results suggest that in normal tissues, endothelial functions may be regulated by VEGF produced by some endocrine cells and that a VEGF/VEGFR binding mechanism may be involved in tumorigenesis, but not in tumor progression and aggressiveness. Hum Pathol 34:18-27. Copyright 2003, Elsevier Science (USA). All rights reserved.

Key words: vascular endothelial growth factor; vascular endothelial growth factor receptor; angiogenesis; microvessel density; digestive endocrine tumor.

Abbreviations: IR, immunoreactive; VEGF, vascular endothelial growth factor; VEGFR, vascular endothelial growth factor receptor.

Tumor-induced angiogenesis depends on the production by tumor cells of proangiogenetic growth factors, which overcome other factors that tend to keep existing vessels quiescent and stable. This process involves several molecules, including those that regulate the maintenance and destruction of perivascular milieu (extracellular matrix and perivascular cells), as well as those stimulating endothelial cell division and migration. ${ }^{6}$ The best-characterized proangiogenetic factor is vascular endothelial growth factor (VEGF), which acts specifically on vascular endothelium, the principal expressor of VEGF receptors (VEGFRs). VEGF promotes endothelial proliferation and sprouting processes, which lead to the formation of new microvessel-like structures. ${ }^{6}$ The production of VEGF by tumor cells is thought to contribute to the onset of tumor-associated angiogenesis.

The VEGF family includes at least 4 molecules. The molecule commonly called "VEGF" corresponds specifically to VEGF-A, the best-known factor. VEGF-B probably plays an important role in vasculogenesis and may also have other functions, including activation of invasive enzymes on endothelial cells. VEGF-C has been reported to be a potential lymphoangiogenetic factor, whereas the role of VEGF-D is less well defined. ${ }^{3}$

Endocrine tumors of the digestive system are a heterogeneous group of neoplasms showing variable 
TABLE 1. Clinicopathologic Features and VEGF, VEGFR1, and VEGFR2 Expression in Gut and Pancreatic Endocrine Tumors

\begin{tabular}{|c|c|c|c|c|c|c|c|c|c|c|c|}
\hline Type & Site & $\operatorname{Sex} M / F$ & $\begin{array}{c}\text { Average } \\
\text { Age (range) } \\
\text { (years) }\end{array}$ & $\begin{array}{c}\text { Average } \\
\text { Size (range) } \\
(\mathrm{cm})\end{array}$ & Malignant & Syndrome & MVD & $\begin{array}{l}\text { Vascular } \\
\text { Invasion }\end{array}$ & VEGF & VEGFR1 & VEGFR2 \\
\hline \multirow[t]{2}{*}{ ECL cell } & Stomach & $1 / 3$ & $70(63-76)$ & 0.5 & $0 / 4$ & $0 / 4$ & 167 & $0 / 4$ & $0 / 4$ & $0 / 4$ & $2 / 4$ \\
\hline & Stomach & $1 / 1$ & $49(43-56)$ & $5(2-8.3)$ & $2 / 2$ & $0 / 2$ & 86 & $0 / 2$ & $0 / 2$ & $1 / 2$ & $1 / 2$ \\
\hline D cell & $*$ & $1 / 4$ & $48(38-52)$ & $2.8(1.5-5)$ & $5 / 5$ & $1 / 5$ & 126.2 & $3 / 4$ & $1 / 5$ & $1 / 5$ & $4 / 5$ \\
\hline \multirow[t]{2}{*}{ G cell } & Duodenum & $1 / 3$ & $51(42-62)$ & $0.7(0.5-1)$ & $0 / 2$ & $0 / 3$ & 158.7 & $0 / 4$ & $4 / 4$ & $4 / 4$ & $2 / 4$ \\
\hline & Pancreas & $0 / 2$ & $56(40-73)$ & $1.7(1.5-2)$ & $2 / 2$ & $2 / 2$ & 79 & $2 / 2$ & $2 / 2$ & $2 / 2$ & $2 / 2$ \\
\hline \multirow[t]{3}{*}{ EC cell } & Ileum-colon & $9 / 9$ & $59(39-89)$ & $2.5(1.5-8)$ & $19 / 19$ & $1 / 19$ & $102 \dagger$ & $11 / 18$ & $9 / 19$ & $12 / 19$ & $12 / 18$ \\
\hline & Appendix & $5 / 6$ & 42 (14-95) & $0.9(1.4-2.5)$ & $0 / 11$ & $0 / 11$ & 67.4 & $0 / 11$ & $6 / 10$ & $6 / 10$ & $6 / 10$ \\
\hline & Pancreas & $0 / 2$ & $62(50-75)$ & $2.5(2-3)$ & $0 / 2$ & $0 / 2$ & 176.5 & $0 / 2$ & $1 / 2$ & $2 / 2$ & $2 / 2$ \\
\hline L cell & Rectum & $2 / 1$ & $35(24-66)$ & $0.9(0.3-1.5)$ & $0 / 3$ & $0 / 3$ & 51 & $0 / 2$ & $2 / 3$ & $2 / 3$ & $1 / 3$ \\
\hline GP & Duodenum & $1 / 0$ & 79 & 6 & $1 / 1$ & $0 / 1$ & 239 & $1 / 1$ & $1 / 1$ & $0 / 1$ & $1 / 1$ \\
\hline VIPomas & Pancreas & $1 / 1$ & $64(57-72)$ & $7.5(5-10)$ & $2 / 2$ & $2 / 2$ & 188 & $1 / 2$ & $2 / 2$ & $1 / 2$ & $2 / 2$ \\
\hline B cell & Pancreas & $0 / 4$ & $52(50-54)$ & $1.6(1-2.5)$ & $0 / 4$ & $4 / 4$ & 163 & $0 / 4$ & $3 / 4$ & $2 / 4$ & $3 / 4$ \\
\hline PP cell & Pancreas & $0 / 1$ & 59 & 8 & $1 / 1$ & $0 / 1$ & 135 & $1 / 1$ & $1 / 1$ & $1 / 1$ & $1 / 1$ \\
\hline A cell & Pancreas & $0 / 3$ & $63(60-66)$ & $1.4(1-2.1)$ & $0 / 4$ & $0 / 4$ & 358 & $0 / 4$ & $0 / 3$ & $3 / 3$ & $2 / 3$ \\
\hline $\mathrm{N}$ cell & Pancreas & $1 / 0$ & 67 & 6.5 & $0 / 1$ & $0 / 1$ & 152 & $0 / 1$ & $0 / 1$ & $0 / 1$ & $1 / 1$ \\
\hline \multicolumn{12}{|l|}{ Undefined } \\
\hline cell & Pancreas & $2 / 0$ & $60(58-62)$ & $2.5(2-3)$ & $2 / 2$ & $0 / 2$ & 136.5 & $2 / 2$ & $1 / 2$ & $0 / 2$ & $1 / 2$ \\
\hline PDEC & Various** & $14 / 4$ & $64(52-72)$ & $5.3(2-10)$ & $18 / 18$ & $0 / 18$ & 76.4 & $18 / 18$ & $7 / 18$ & $7 / 18$ & $12 / 18$ \\
\hline
\end{tabular}

Abbreviations: GP, gangliocytic paraganglioma; PDEC, poorly differentiated endocrine carcinoma.

*4 cases were duodenal, and 1 case was pancreatic.

**7 gastric, 2 duodenal, 7 colonic, and 2 pancreatic.

†Ileal and colonic MVDs were 95 and 109, respectively, statistically higher $(P=0.03)$ than that of appendiceal tumors (MVD, 67.4).

hormone production, biological aggressiveness, and behavior that often are not predictable on the basis of histopathologic analysis alone. ${ }^{7,8}$ Although several immunohistochemical and molecular parameters (i.e., Ki67 expression, p53 nuclear accumulation, overexpression of oncoproteins and growth factors) have been studied, ${ }^{7,9-12}$ the biological mechanisms involved in the pathogenesis, growth, and metastatic spread of digestive endocrine tumors are not well understood. Endocrine tumors of the gut and pancreas are known to be well vascularized, but to the best of our knowledge, no data on angiogenesis and its biological meaning for such tumors are available. To date, although a few studies on VEGF expression in digestive endocrine neoplasms have been reported, ${ }^{13-15}$ the roles of VEGF in tumorigenesis, tumor growth, and aggressiveness remain unclear.

In this study we evaluated the expression of VEGF and its receptors (VEGFR1-flt1 and VEGFR2-flk1) in a series of gut and pancreatic endocrine tumors and compared this with expression in related normal endocrine cells. In addition, we investigated whether the immunohistochemical expression of VEGF, VEGFR1, and VEGFR2 was correlated with microvessel density (MVD) or the type and malignancy of tumors.

\section{MATERIALS AND METHODS}

\section{Tissues}

Surgically resected normal tissues and 84 endocrine tumors of the digestive system (64 of the gut and 20 pancreatic) were fixed in buffered formalin (formaldehyde $4 \% \mathrm{w} / \mathrm{v}$ and acetate buffer $0.05 \mathrm{M}, \mathrm{pH} 7.4$ ) and embedded in paraffin wax. Clinicopathologic data for the tumors are summarized in
Table 1. For histopathologic evaluation, $5-\mu \mathrm{m}$ thick sections were stained with hematoxylin and eosin $(\mathrm{H} \& \mathrm{E})$ and Grimelius' silver stains. In addition, specimens of both digestive endocrine tumors and normal tissues were fixed in a mixture of paraformaldehyde and glutaraldehyde for electron microscopy and ultrastructural immunocytochemistry investigations.

\section{Immunohistochemistry}

Endocrine tumors were characterized using the antibodies and antisera listed in Table 2. Specific polyclonal and monoclonal antibodies (Santa Cruz Biotechnology, Santa Cruz, CA) were used to study VEGF, VEGFR1, and VEGFR2 expression. The anti-VEGF antibody was a rabbit high-affinity purified polyclonal antibody raised against a peptide mapping at the amino acid terminus of human VEGF. The antiVEGFR1 (flt-1) was a rabbit high-affinity purified polyclonal antibody directed against a peptide mapping at the carboxy terminus of human flt-1. The anti-VEGFR2 (flk-1) was a mouse monoclonal $\operatorname{IgG}_{1}$ antibody raised against a recombinant protein corresponding to amino acids 1158 to 1345 , mapping at the carboxy terminus of flk-1 of mouse origin, which recognizes the same sequence of human flk-1.

The 3- $\mu$ m-thick sections were mounted on poly-L-lysinecoated slides and then deparaffinized and hydrated through graded alcohols to water. Endogenous peroxidase activity was removed by dipping the sections in 3\% hydrogen peroxide for 10 minutes at room temperature. The sections were then incubated with specific antibodies (Table 2) for 18 to 20 hours at $4^{\circ} \mathrm{C}$. The avidin-biotin-peroxidase procedure was performed next. Peroxidase activity, indicating the presence of the antigen for which we were looking, was finally revealed by $0.03 \% 3,3^{\prime}$ diaminobenzidine, and nuclei were counterstained with Harris' hematoxylin. Colocalization studies to identify the specific cell types expressing VEGF, VEGFR1, and VEGFR2 were performed using double-label immunostains as previously reported. ${ }^{12}$ Sections immunostained for glucagon, 
TABLE 2. Antibodies and Antisera Used

\begin{tabular}{lcll}
\hline \multicolumn{1}{c}{ Antibodies/Antisera } & P/M (clone) & Dilution & \\
\hline Glicentin-glucagon & & $1: 2500$ & Milab, Malamo, Sweden \\
Glucagon & $\mathrm{P}$ & $1: 1250$ & Milab, Malamo, Sweden \\
Pancreatic polypeptide & $\mathrm{P}$ & $1: 4000$ & Cambridge Research Biochemicals, Cambridge, UK \\
Insulin & $\mathrm{P}(\mathrm{AE} 9 \mathrm{D} 6)$ & $1: 200$ & BioGenex Laboratories, San Ramon, CA \\
Somatostatin & $\mathrm{P}$ & $1: 500$ & Dako, Copenhagen, Denmark \\
Somatostatin & $\mathrm{M}(\mathrm{YC} 7)$ & $1: 10$ & Immunochimica Labometrics, Milan, Italy \\
Secretin & $\mathrm{P}$ & $1: 500$ & Milab, Malamo, Sweden \\
Serotonin & $\mathrm{M}(\mathrm{YC5})$ & $1: 50$ & Biogenesis, Bournemouth, UK \\
Peptide YY & $\mathrm{P}$ & $1: 1000$ & Biogenesis, Bournemouth, UK \\
Vasoactive intestinal peptide & $\mathrm{P}$ & $1: 12000$ & Milab, Malamo, Sweden \\
C-terminus gastrin-CCK-cerulein & $\mathrm{M}(\mathrm{B} 4)$ & $1: 10000$ & Farmitalia, Milan, Italy \\
Gastrin 34 & $\mathrm{P}$ & $1: 500$ & Cambridge Research Biochemicals, Cambridge, UK \\
Neurotensin & $\mathrm{P}$ & $1: 6000$ & Milab, Malamo, Sweden \\
CD31 & $\mathrm{M}(\mathrm{JC} / 704)$ & $1: 20$ & Dako, Copenhagen, Denmark \\
CD34 & $\mathrm{M}(\mathrm{My} 10)$ & $1: 10$ & Becton Dickinson, San Jose, CA \\
Factor VIII-related antigen & $\mathrm{P}$ & $1: 1$ & Biomeda, Hayward, CA \\
Vascular endothelial growth factor & $\mathrm{P}$ & $1: 400$ & Santa Cruz Biotechnology, Santa Cruz, CA \\
Vascular endothelial growth factor receptor 1 & $\mathrm{P}$ & $1: 200$ & Santa Cruz Biotechnology, Santa Cruz, CA \\
Vascular endothelial growth factor receptor 2 & $\mathrm{M}(\mathrm{A}-3)$ & $1: 600$ & Santa Cruz Biotechnology, Santa Cruz, CA \\
\hline
\end{tabular}

Abbreviation: $\mathrm{P} / \mathrm{M}$, polyclonal/monoclonal.

glucagon-glicentin, and somatostatin (polyclonal) were pretreated with $0.003 \%$ subtilisin (protease type XXVII or Nagarse protease; Sigma, St Louis, MO) in $0.05 \mathrm{M}$ Tris-buffered saline, $\mathrm{pH} 7.4$, at room temperature for 10 minutes. Sections immunostained for VEGF, VEGFR1, and CD31 were pretreated with $0.05 \%$ trypsin (Sigma) in $0.05 \mathrm{M}$ Tris-buffered saline, $\mathrm{pH} 7.4$, at $37^{\circ} \mathrm{C}$ for 20 minutes, whereas sections immunostained for VEGFR2 were pretreated with an EDTA buffer, $\mathrm{pH} 8$, in a microwave oven at $700 \mathrm{~W}$ for 10 minutes.

Specificity controls consisted of (1) absorption of every antibody with 10 to $20 \mathrm{nmol}$ of related antigen, (2) substitution of the primary antibody with nonimmune serum of the same species at the same dilution, and (3) the use of control tissues with or without the pertinent antigens. The specificity of antibodies directed against VEGF, VEGFR1, and VEGFR2 was also tested previously. ${ }^{15,16}$

\section{Electron Microscopy and Ultrastructural Immunocytochemistry}

For ultrastructural analysis, small samples of gastrinomas and normal gut tissues were fixed in a mixture of $2 \%$ paraformaldehyde and $2 \%$ glutaraldehyde in $0.05 \mathrm{M}$ cacodylate buffer, $\mathrm{pH} 7.4$, for 2 hours at $4^{\circ} \mathrm{C}$. They were then postfixed in osmium tetroxide ( $1 \%$ in $0.1 \mathrm{M}$ cacodylate buffer, $\mathrm{pH} 7.4$ ) for 1 hour at room temperature and embedded in EponAraldite (Fluka, Buchs, Switzerland). Ultrathin sections were collected on Formvar-coated nickel, 200-mesh grids, counterstained with uranyl acetate and lead citrate, and observed with an electron microscope (Model CM 120; Philips, The Netherlands).

Ultrastructural immunocytochemistry was done using the immunogold labeling technique. Small tissue samples were fixed in a solution of $2 \%$ paraformaldehyde and $0.5 \%$ glutaraldehyde in $0.05 \mathrm{M}$ cacodylate buffer, $\mathrm{pH} 7.4$, for 2 hours at $4^{\circ} \mathrm{C}$ and embedded in London White resin (Polysciences, Warrington, PA). Ultrathin sections were preincubated for 5 minutes with ovoalbumin in $0.01 \mathrm{M}$ Tris-buffered $0.5 \mathrm{M} \mathrm{NaCl}, \mathrm{pH} 7.4$, followed by incubation for 12 hours at $4^{\circ} \mathrm{C}$ with antibodies directed against VEGF, VEGFR1, and VEGFR2. After 3 washes (10 minutes each) in Tris-buffered $\mathrm{NaCl}$ to remove nonspecifically bound and unbound antibod- ies, sections stained with anti-VEGF and anti-VEGFR1 antibodies were incubated for 1 hour with 1:50 diluted goldtagged goat anti-rabbit Ig antibodies (EY Laboratories, San Mateo, CA), and sections stained for VEGFR2 were incubated with 1:20 diluted gold-tagged horse anti-mouse Ig antibodies (EY Laboratories). Finally, the grids were washed in Trisbuffered $\mathrm{NaCl}$, rinsed in distilled water, dried, and stained for 5 minutes with aqueous uranyl acetate $(5 \%)$ and for 5 minutes with Reynolds lead citrate. The sections were finally examined with a Philips CM 120 electron microscope.

\section{Evaluation Of Intratumor MVD}

Intratumor MVD, representing the number of microvessels present in a well-defined area of the tumor, was evaluated using the criteria described by Weidner. ${ }^{17}$ The count was performed on sections immunostained with antibodies directed against endothelial antigens CD31, CD34, and factor VIII-related antigen. Areas of highest vascularization were found by scanning tumor sections at low power ( $\times 40$ and $\times 100$ total magnification, corresponding to areas of $19.62 \mathrm{~mm}^{2}$ and $3.141 \mathrm{~mm}^{2}$, respectively) and selecting those areas with the greatest density of distinct factor VIII-related antigen-, CD31-, and CD34-stained microvessels. After the area of highest vascularization was identified, individual microvessel counts were made at $\times 200$ magnification $\left(0.785 \mathrm{~mm}^{2}\right.$ area $)$ in 3 different fields using a Leitz Diaplan microscope (Leitz Microscope, Weitzmar, Germany). Any highlighted endothelial cell or endothelial cell cluster clearly separate from adjacent microvessels, tumor cells, and other connective tissue elements was considered a single, countable microvessel. Even those distinct clusters of brown-staining endothelial cells, which might be from the same microvessel snaking its way in and out of the section, were considered distinct, countable, and separate microvessels. The presence of a vessel lumen was not necessary for a structure to be defined as a microvessel, and red cells were not used to define a vessel lumen. According to Bosari et al, ${ }^{18}$ vessels of a caliber larger than approximately 8 red blood cells and vessels with a thick muscular wall were excluded from the count. Using the same criteria, 

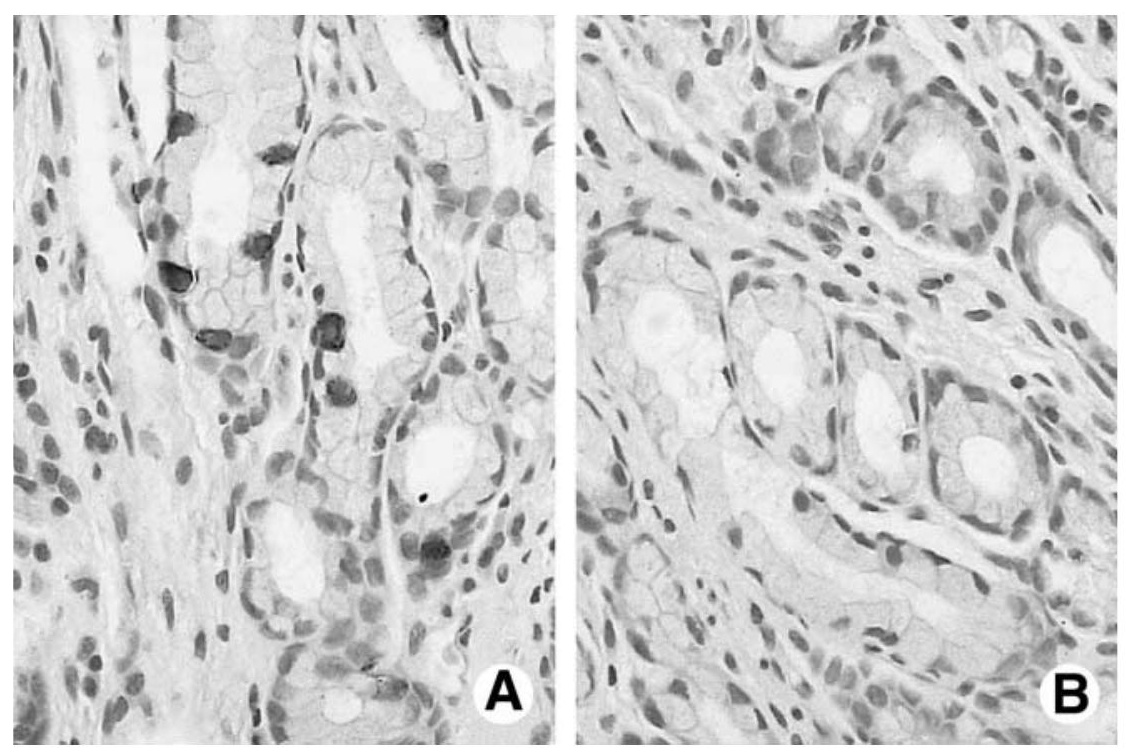

FIGURE 1. (A) VEGF immunoreactivity in several endocrine cells of the antral mucosa. (B) After absorption of the anti-VEGF antibody with the VEGF antigen, the immunoreaction is completely abolished. (Immunoperoxidase with hematoxylin counterstaining.)

the number of microvessels was also counted in normal mucosa of the gut and in pancreatic islets.

\section{Statistical Analysis}

Expression of VEGF, VEGFR1, and VEGFR2 among the various tumor types was evaluated statistically using Fisher's exact test. The relationship between VEGF, VEGFR1, VEGFR2 expression and vessel density was evaluated using Wilcoxon's rank sum test.

\section{RESULTS}

\section{Normal Tissues}

VEGF immunoreactivity was found in several endocrine cells of the antral and duodenal mucosa, but not in the other portions of the gut (Fig 1). The immunoreactivity was cytoplasmic, granular, and intense. Colocalization studies indicated that gastrin-producing G cells were VEGF immunoreactive, whereas the other normal endocrine cells of the gut, including somatostatin-, motilin-, secretin-, and serotonin-producing enterochromaffin cells, were negative. Ultrastructural immunocytochemical analysis demonstrated that VEGF was localized within the secretory granules of $G$ cells, but not in the other types of normal endocrine cells of the antral and duodenal mucosa (Fig 2). In the pancreas, an intense VEGF immunoreactivity was seen in some islet cells. VEGF-IR cells were numerous in the islets of the PP-rich part of the pancreatic head (Fig 3), where double-label immunohistochemistry demonstrated that they corresponded to PP cells. VEGF-IR cells were rare in the other islets of the head and in the islets of the body and tail. In addition to endocrine cells, VEGF immunoreactivity was observed in some endothelial cells, in ganglion cells of the myenteric plexus, and in acinar cells of the pancreas. Here the intensity of VEGF staining was weaker than that observed in endocrine cells.

VEGFR1 immunoreactivity was observed in rare endocrine cells of the antroduodenal mucosa and of the pancreatic islets, identified morphologically. The pattern of immunoreactivity was cytoplasmic and granular, although increased staining at the membrane level was observed in some cells. No VEGFR2 immunoreactivity was observed in normal endocrine cells distributed along the gut or in the pancreatic islets. Endothelial cells in all gut and pancreatic samples examined were positively stained by both the antiVEGFR1 and VEGFR2 antibodies. The mean number of microvessels in normal gut mucosa and in pancreatic islets is reported in Table 3.

\section{Endocrine Tumors}

VEGF-IR cells were identified in 40 of $83(48 \%)$ endocrine tumors. With the exception of ECL-cell, Acell, and neurotensin (N)-cell neoplasms, VEGF-IR cells were observed in all of the neoplasms investigated but with some differences among the different functional types of tumors (Table 1). In addition, the percentage of positive cells and the intensity of the immunostaining also varied among various types. In particular, all G-cell tumors, whether or not associated with the Zollinger-Ellison syndrome, were VEGF positive (Fig 4) and had the highest percentage of VEGF-positive cells (mean percentage of positive cells, 64\%). Sixteen of 31 $(51.6 \%)$ EC-cell tumors of the gut were also positive (Fig 5), but their mean percentage of positive cells was lower $(38 \%)$ than that of gastrinomas. Among pancreatic endocrine tumors, 3 of 4 insulinomas, 1 of 1 PP-cell tumor, 2 of 2 VIPomas were VEGF positive (Fig 6). VEGF expression was not significantly correlated with 

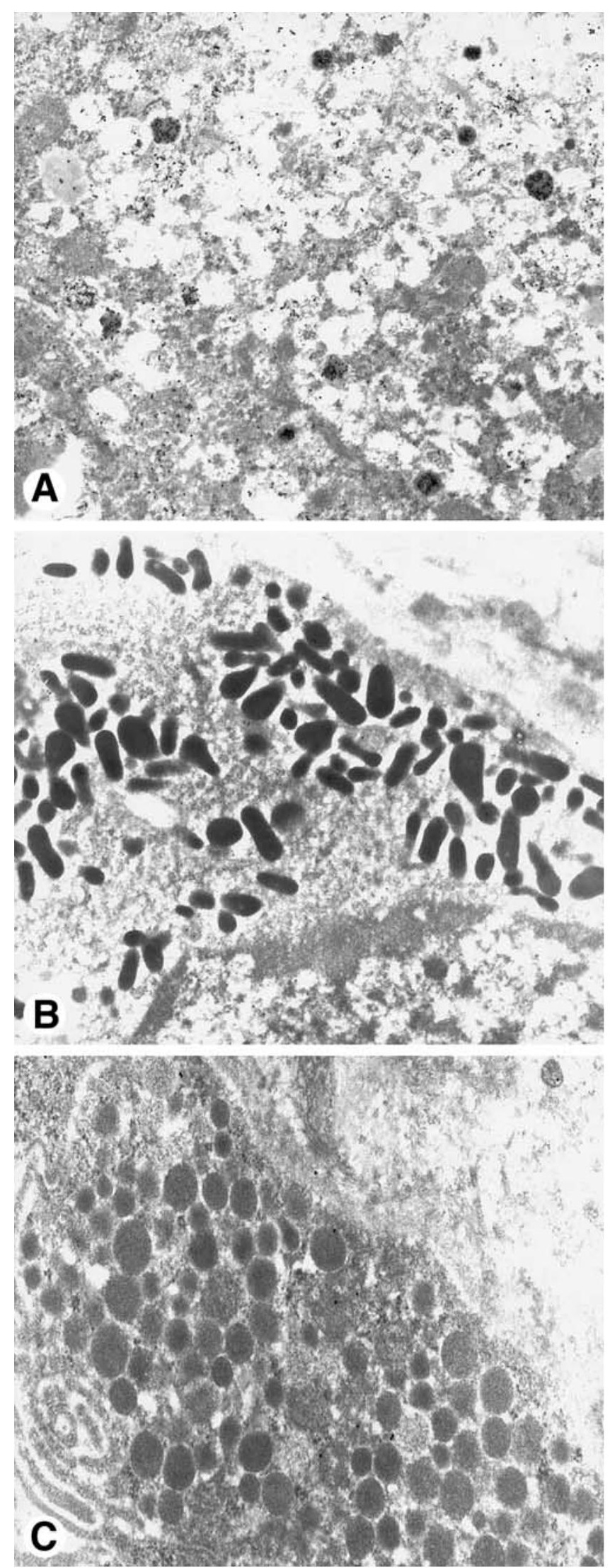

the presence of endocrine symptoms, tumor diameter, metastatic disease, MVD, or vascular invasion. Electron microscope immunocytochemical analysis performed on 2 cases of gastrin cell tumors showed that, as in normal G cells, the VEGF immunoreactivity was localized within the secretory granules (Fig 4).

VEGFR1 immunoreactivity was found in 44 of 82 $(53.6 \%)$ endocrine tumors, mainly in insulinomas and G cell, EC cell, L cell, and A cell neoplasms. Among these, the strongest immunostaining and the highest percentage of VEGFR1-IR cells were observed in gastrinomas (Fig 4). VEGFR2-IR cells were observed in 55 of $82(67 \%)$ tumors investigated, without any significant predilection for a specific tumor type (Fig 4). As for VEGF expression, the positivity of both VEGFR1 and VEGFR2 was not correlated with MVD, vascular invasion, or tumor malignancy. In addition to tumor cells, vascular endothelial cells expressed both VEGFRs. At the ultrastructural level, we were unable to obtain convincing and specific immunoreactivities with the antibodies directed against VEGFR1 and VEGFR2. Thirtyfour tumors coexpressed VEGF and at least 1 of 2 receptors: 8 tumors coexpressed VEGF and VEGFR1, 7 tumors coexpressed VEGF and VEGFR2, and 19 neoplasms coexpressed VEGF, VEGFR1, and VEGFR2.

Unlike the expression of VEGF and of its receptors, we observed a relationship between malignancy and MVD for intestinal EC-cell tumors. In particular, EC-cell neoplasms of the ileocolonic region, which were all malignant, had a statistically greater $(P=0.03)$ MVD (mean value, 102) than that of appendiceal ones, which were all benign (mean value, 67.4). On the other hand, considering all 84 tumors without differentiating them in terms of type and site, no relationship between MVD and malignancy was observed.

The mean value of MVD in endocrine tumors is reported in Table 3. No significant differences in MVD were observed between normal and neoplastic tissues in gastric, duodenal, and colonic mucosa. In contrast, ileal endocrine tumors had a significantly higher number of vessels than the normal ileal mucosa $(P<0.05)$. In the pancreas we found the opposite; the number of capillaries in the normal islets was statistically higher $(P=$ 0.01 ) than that of pancreatic endocrine tumors.

\section{DISCUSSION}

In this study we have investigated the expression of VEGF, VEGFR1, and VEGFR2 in normal endocrine cells of the gut and pancreas and in a large series of endocrine tumors of the digestive system. We observed strong VEGF immunoreactivity in several endocrine cells of the antral and duodenal mucosa, corresponding to gastrin-producing $\mathrm{G}$ cells. Our observations were

FIGURE 2. Ultrastructural immunocytochemistry demonstrates that VEGF immunoreactivity is localized in the secretory granules of $G$-cells (A), whereas secretory granules of EC-cells (B) and D-cells (C) are completely negative. (Original magnification (A, B) $\times 18,400$, (C) $\times 29,900$.) 

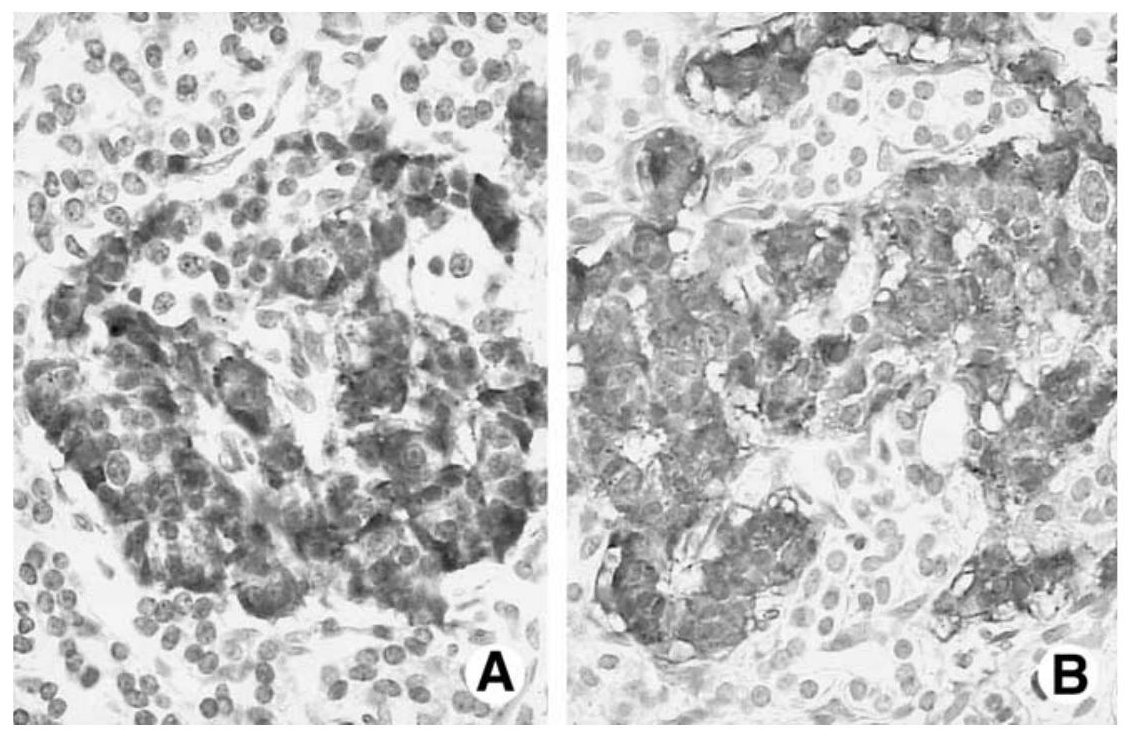

FIGURE 3. VEGF immunoreactivity in almost all cells of an islet localized in the PP-rich lobe (A), where the islets show a trabecular structure and are mainly composed by PP-cells as demonstrated by strong immunoreactivity for PP (B). (Immunoperoxidase with hematoxylin counterstaining.)

confirmed by the immunoelectron microscopic localization of VEGF in secretory granules of G cells but not in those of other endocrine cell types of the gut. In the pancreas we observed strong VEGF immunoreactivity in PP cells of the islets, whereas $\mathrm{B}, \mathrm{A}$, and $\mathrm{D}$ cells were negative. The expression of VEGF in normal endocrine cells of the gut and pancreas has been poorly investigated, and the reported results are different and contradictory in some studies relating to the antibodies used and the series and species investigated. ${ }^{13-15,19,20,22-24}$

The significance of VEGF expression in endocrine cells of the gut and pancreas is not clear. The fact that it is present in the secretory granules along with the hormone, as demonstrated in the present study, may suggest that VEGF is released together with the hormone. VEGF may contribute to the maintenance of the endothelial cell subsets associated with endocrine tissues, especially considering that VEGF has been demonstrated to induce fenestration in neovessels ${ }^{25}$ and

TABLE 3. Mean Value of Microvessels in Normal Tissues and in Endocrine Tumors

\begin{tabular}{|c|c|c|c|c|}
\hline \multirow[b]{2}{*}{ Site } & \multicolumn{2}{|c|}{ Normal } & \multicolumn{2}{|c|}{ Tumors } \\
\hline & Mean & $\begin{array}{c}95 \% \\
\text { Confidence } \\
\text { Interval }\end{array}$ & Mean & $\begin{array}{c}95 \% \\
\text { Confidence } \\
\text { Interval }\end{array}$ \\
\hline Stomach* & 128.5 & $117.62-140.1$ & 117.69 & $111.86-123.74$ \\
\hline Duodenum* & 140 & $124.00-157.39$ & 130.54 & $123.88-137.47$ \\
\hline Ileum $†$ & 67.66 & $58.67-77.64$ & 95.14 & $90.10-100.39$ \\
\hline Colon* & 66.66 & $57.74-76.57$ & 84 & $79.26-88.94$ \\
\hline Pancreatic islets§ & 279.4 & 264-294 & 174 & 168-179 \\
\hline
\end{tabular}

*The difference is not statistically significant.

$\dagger$ The difference is statistically significant $(P<0.05)$.

$\S$ The difference is statistically significant $(P=0.01)$. that islet capillaries are lined by fenestrated endothelial cells. ${ }^{26}$

Little is known about the expression of VEGF receptors in normal endocrine cells of the gut and pancreas. Both VEGFR1 and VEGFR2 mRNAs have been found to be present in islet endothelial cells, whereas endocrine cells seemed to be negative. ${ }^{13,27}$ No VEGFR2 immunoreactivity was seen in normal endocrine cells of the gut and pancreas, whereas only rare and scattered endocrine cells were VEGFR1 positive. Taken together, these results suggest that in normal conditions, VEGF/ VEGFRs binding is not an important mechanism in the modulation of biological functions of gut and pancreatic endocrine cells, but, as has been reported earlier, it may play a role in inducing vessel permeability and modulating other endothelial functions.

Our results proving that VEGF and its receptors are widely expressed in endocrine tumors of the gut and pancreas add new information to the previous investigations on this subject. ${ }^{14,15}$ In the study of Terris et al, ${ }^{15}$ VEGF expression was found in 25 gut carcinoids, represented mainly by midgut tumors ( 16 cases), and in 16 pancreatic endocrine tumors, represented mainly by nonfunctioning neoplasms (9 cases). In addition, Kuroda et $\mathrm{al}^{14}$ reported VEGF expression in 3 of 7 insulinomas but no expression in other types of pancreatic endocrine neoplasms, including 1 A-cell, 3 D-cell, and 1 G-cell tumors. Our data confirm that EC-cell tumors, probably corresponding to the midgut carcinoids described by Terris et al, ${ }^{15}$ do express VEGF, although we also observed a strong VEGF immunoreactivity in G-cell tumors, both duodenal and pancreatic, and in rectal L-cell carcinoids. Our results regarding VEGF expression in pancreatic endocrine tumors (Table 4) are also in agreement with those previously reported; ${ }^{14,15}$ in our study, however, pancreatic tumor types that had not previously been examined for VEGF expression, such 

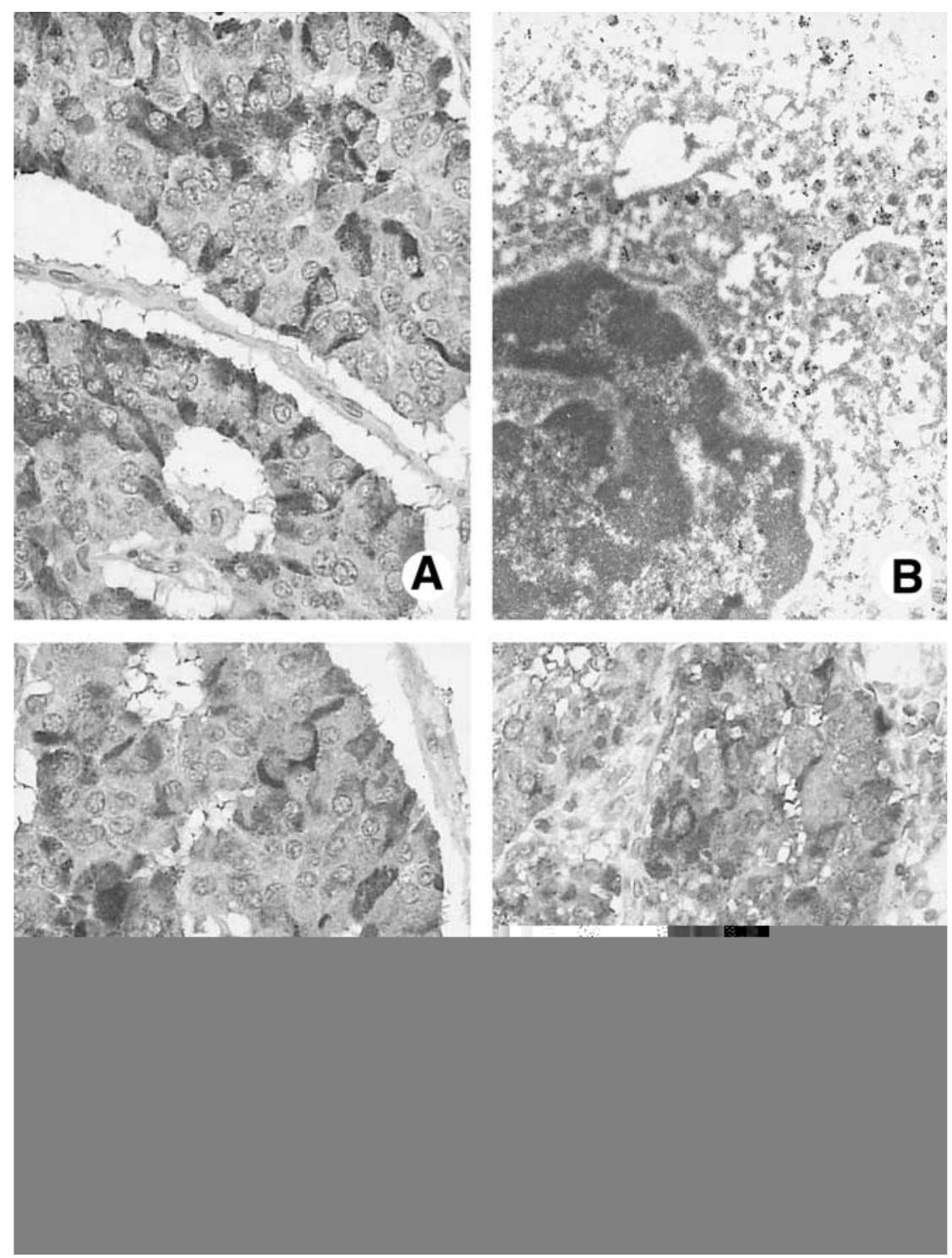

FIGURE 4. Duodenal gastrinoma. (A) VEGF immunoreactivity in the cytoplasm of numerous cells. (B) As in normal cells, the immunostaining is localized in the secretory granules. (Original magnification $\times 29,900$.) The same tumor is also positive for VEGFR 1 (C) and VEGFR2 (D). (Immunoperoxidase with hematoxylin counterstaining.)

as EC-cell tumors, neurotensin-cell tumors, VIPomas, and poorly differentiated endocrine carcinomas, were also analyzed.

The expression of VEGF by gut and pancreatic endocrine tumors supports the hypothesis that this growth factor may be involved in tumor angiogenesis. It assumes a particular interest considering that these tumors are generally well vascularized. However, we have not found any significant relationship between VEGF expression and MVD. Although this result may seem contradictory, it is not really surprising. The fact that VEGF has no correlation with MVD does not rule out a crucial role of VEGF as a key factor in tumor angiogenesis. Angiogenesis is a very complicated biological mechanism in which several growth factors cooperate, with different power, to stimulate vascular proliferation. Although VEGF seems to be the most important proangiogenetic factor, it has recently been demonstrated that VEGF induction of angiogenesis is potentiated by the synergistic action of other growth factors, including acidic and basic fibroblast growth factors ${ }^{28,29}$ and hepatocyte growth factor. ${ }^{30}$ In this context, it is of interest to recall that endocrine tumors of the digestive system, and in particular EC-cell tumors of the midgut, are known to produce several proangiogenetic factors, including acidic and basic fibroblast growth factors, transforming growth factor- $\alpha$, and hepatocyte growth factor. ${ }^{9,11,31}$ Thus the relationship between VEGF and MVD that we have investigated may be highly influenced by the presence of other growth factors.

The localization of the two VEGF receptors in digestive endocrine tumors has not been previously reported. We found VEGFR1 expression in 44 of 82 


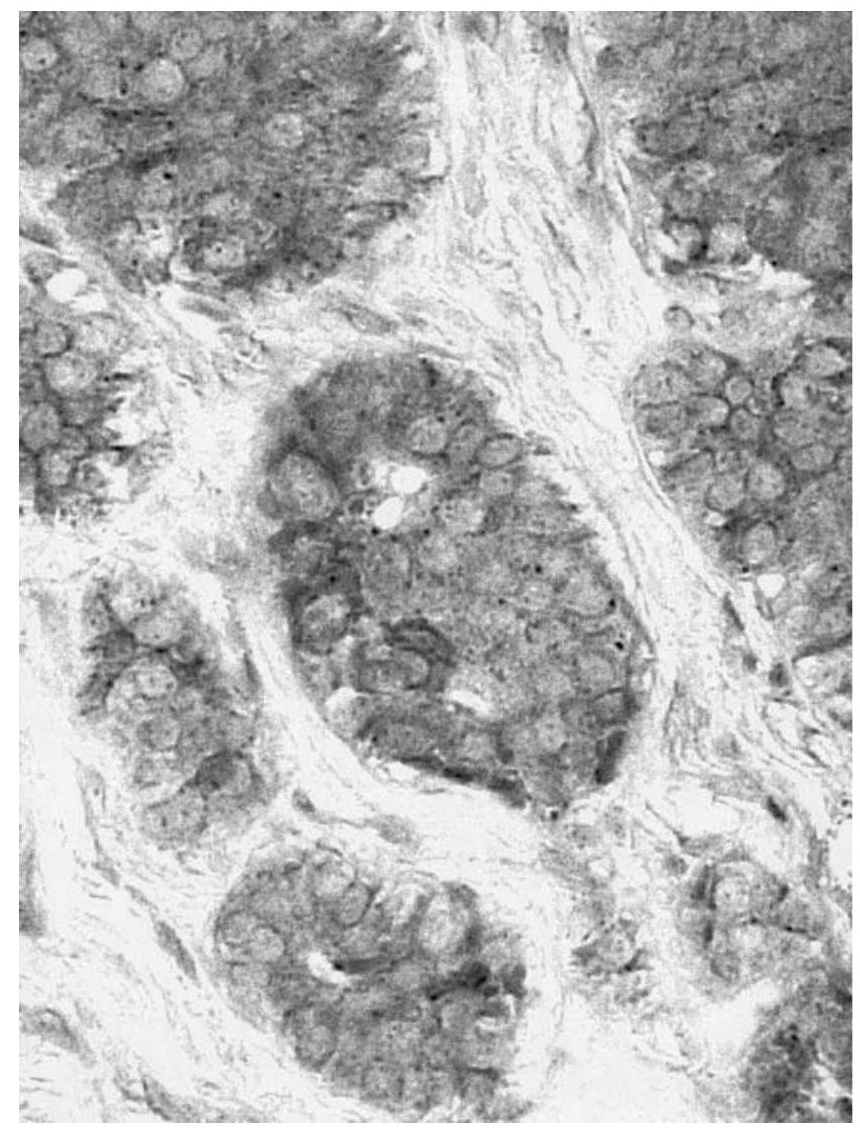

FIGURE 5. VEGF immunoreactivity in a malignant ileal EC-cell tumor. (Immunoperoxidase with hematoxylin counterstaining.)

(53.6\%) tumors and VEGFR2 expression in 55 of 82 $(67 \%)$ tumors. The expression of the 2 receptors did not correlate with a specific tumor type although a coexpression of both VEGFRs was mainly observed in gastrinomas and EC-cell tumors. VEGFRs are very poorly expressed in normal endocrine cells of the gut and pancreas, whereas they appear to be expressed de novo in several tumor types, suggesting their involvement in the mechanisms regulating digestive endocrine tumorigenesis. In this context, it is well known that both de novo expression and overexpression are involved in the oncogenetic potential of growth factor receptors with tyrosine-kinase activity ${ }^{32}$ and the de novo expression of growth factor receptors in digestive endocrine tumors has already been described..$^{9,11,12}$ In addition, coexpression of VEGF and VEGFR is strictly associated with malignant transformation in pancreatic cancers and suggests the existence of an autocrine/ paracrine mitogenic loop for pancreatic cancer cells. ${ }^{33}$ The fact that VEGF and its 2 receptors were coexpressed in several tumors (34 cases) suggests that the interaction of VEGF with its receptors is involved in the biology of gastroenteropancreatic endocrine tumors in an autocrine/paracrine fashion. However, in the case of gastroenteropancreatic endocrine tumors, the expression of both VEGFR1 and VEGFR2 did not correlate with tumor malignancy. This finding indicates that

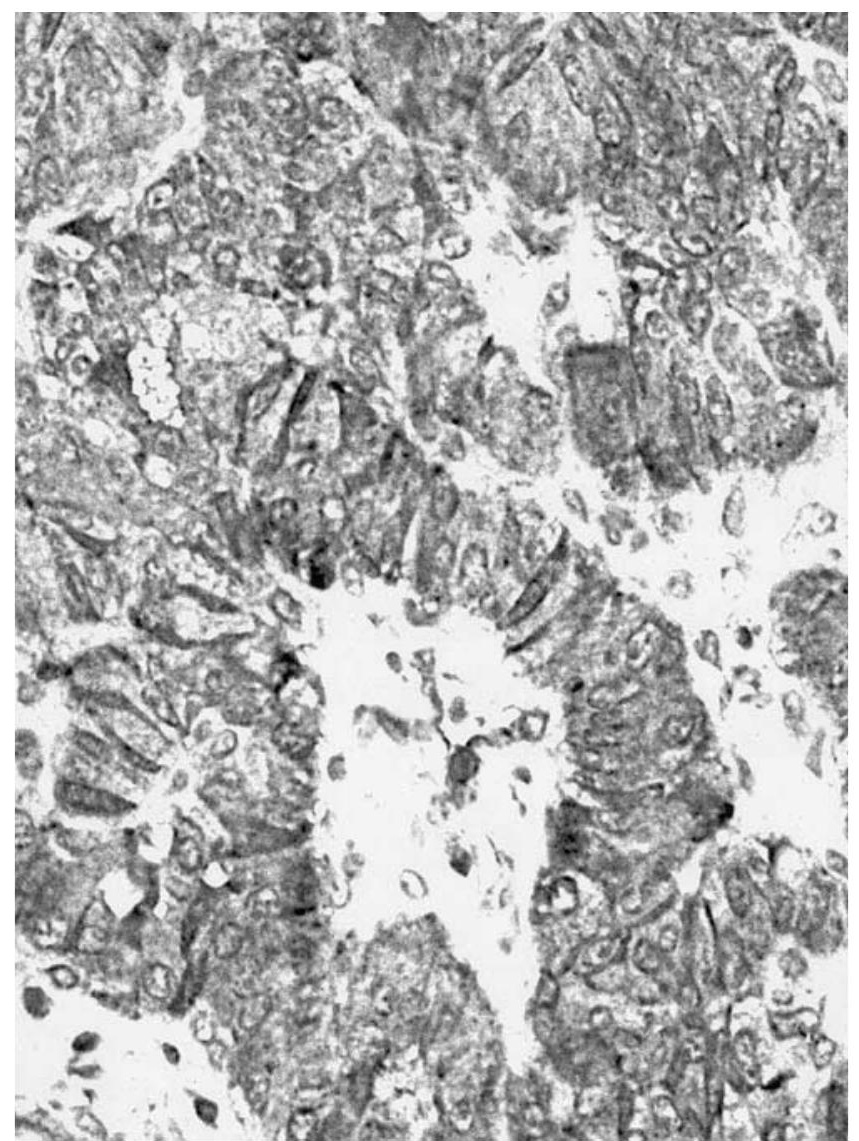

FIGURE 6. VEGF immunoreactivity in a pancreatic VIPoma (Immunoperoxidase with hematoxylin counterstaining.)

VEGFR expression is probably involved in tumor development but does not participate in the regulation of tumor progression, which may be regulated by different growth factors and growth factor receptors, including hepatocyte growth factor, met, and fibroblast growth

TABLE 4. VEGF Expression in Pancreatic Endocrine Tumors From Different Series

\begin{tabular}{lcrrr}
\hline Tumor Type & $\begin{array}{c}\text { Kuroda } \\
\text { et al }^{14}\end{array}$ & $\begin{array}{c}\text { Terris } \\
\text { et al }^{15}\end{array}$ & $\begin{array}{c}\text { Present } \\
\text { Study }\end{array}$ & \multicolumn{1}{c}{ Total } \\
\hline B cell & $3 / 7$ & $2 / 3$ & $3 / 4$ & $8 / 14(57 \%)$ \\
D cell & $0 / 3$ & & $0 / 1$ & $0 / 4$ \\
A cell & $0 / 1$ & $2 / 2$ & $0 / 3$ & $2 / 6(33 \%)$ \\
PP cell & & & $1 / 1^{*}$ & $1 / 1(100 \%)$ \\
G cell & $0 / 1$ & $2 / 2$ & $2 / 2$ & $4 / 5(80 \%)$ \\
EC cell & & & $1 / 2$ & $1 / 2(50 \%)$ \\
N cell & & & $0 / 1$ & $0 / 1$ \\
Undefined cell & & & $1 / 2$ & $1 / 2(50 \%)$ \\
VIPomas & & & $0 / 2$ & $2 / 2(100 \%)$ \\
PDEC & & $1 / 2$ & & $1 / 2(50 \%)$ \\
Calcitonin cell & & $9 / 11$ & & $9 / 11(82 \%)$ \\
NF & & & & $29 / 52(55.7 \%)$ \\
Total & $3 / 12$ & $16 / 20$ & $10 / 20$ & \\
\hline
\end{tabular}

Abbreviations: PDEC, poorly differentiated endocrine carcinoma; NF, nonfunctioning tumors not otherwise specified.

* Only rare cells.

$\dagger$ These tumors also presented PP-positive cells. 
factor receptors. ${ }^{11,12}$ Both VEGFRs were also detected in several endothelial cells, supporting the hypothesis of a paracrine control of endothelial cells by VEGF secreted by tumor cells.

Considering the whole group of digestive endocrine tumors, we did not observe any correlation between MVD and tumor malignancy. However, examining only the subgroup of EC-cell tumors, we found a statistically significant $(P=0.03)$ relationship between these 2 parameters. This finding is interesting and suggests that the malignancy of ileal tumors may be influenced by a more well-developed vascularization in comparison with the appendiceal ones, which are generally benign and express a lower number of vessels. The relationship of MVD and malignancy is also emphasized for EC-cell tumors of the ileum by the significantly higher number of microvessels found in tumors in comparison with the normal ileal mucosa.

The relationship between MVD and prognosis has been investigated in several tumor types. Recent studies have demonstrated that increased MVD is a significant and independent prognostic indicator of breast cancers at early stages. ${ }^{4}$ Studies of other malignancies, including melanomas, prostate, ovarian, gastric, colonic, pancreatic, lung, cervical, and head and neck carcinomas, also support the conclusion that the angiogenesis index is a useful prognostic factor. ${ }^{3,4}$ However, the hypothesis that angiogenesis alone can identify metastatic disease and predict patient survival may be unrealistic for at least 2 main reasons. First, human tumors are heterogeneous, with the various cell populations having different biological properties and producing different biological molecules. Second, metastatization is a sequential and selective process comprising several different steps ${ }^{34}$ not all of which depend on angiogenesis. In the light of these concepts, using the angiogenesis index as a prognostic marker should be considered with caution; it may be useful only for specific neoplasms at specific stages. This is also supported by the fact that MVD has not been found to be related to patient prognosis in some malignancies, including non-small cell carcinomas of the lung ${ }^{16}$, colonic adenocarcinomas, ${ }^{35}$ and pancreatic endocrine tumors. 36

In conclusion, the findings of the present study demonstrate that VEGF is expressed by specific normal endocrine cells of the gut and pancreas and in several digestive endocrine tumors, represented mainly by G-, EC-, B-, and L-cell neoplasms. VEGFRs are widely expressed by cells of several endocrine tumors in addition to endothelial cells, but are not significantly expressed by normal endocrine cells. These results suggest the role of VEGF in modulating endothelial functions in normal tissues. Because VEGF and VEGFR expression was not correlated with MVD and malignancy, we suggest that a VEGF/VEGFR binding mechanism may be involved in the tumorigenesis of digestive endocrine neoplasms, but not in tumor progression and aggressiveness.

\section{REFERENCES}

1. Folkman J, Shing Y: Angiogenesis. J Biol Chem 267:1093110934, 1992

2. Folkman J: What is the evidence that tumors are angiogenesis dependent? J Natl Cancer Inst 82:4-6, 1990

3. Ellis LM, Fidler IJ: Tumor angiogenesis, in Mendelsohn J, Howley PM, Israel MA, et al (eds): The Molecular Basis of Cancer (ed 2). Philadelphia, PA, Saunders, 2001, pp 173-185

4. Shebert GV, Lakshmi MS: Angiogenesis in cancer, in Shebert GV, Lakshmi MS (eds): The Genetics of Cancer: Genes Associated With Cancer Invasion, Metastasis and Cell Proliferation. San Diego, CA, Academic Press, 1997, pp 86-99

5. Chan ASY, Leung SY, Wong MP, et al: Expression of vascular endothelial growth factor and its receptors in the anaplastic progression of astrocytoma, oligodendroglioma, and ependimoma. Am J Surg Pathol 22:816-826, 1998

6. Holash J, Wiegand SJ, Yancopoulos GD: New model of tumor angiogenesis: Dynamic balance between vessel regression and growth mediated by angiopoietin and VEGF. Oncogene 18:5356-5362, 1999

7. Solcia E, Capella C, Klöppel G: Tumors of the pancreas, in Rosai J, Sobin LH (eds): Atlas of Tumor Pathology. Tumors of the Pancreas. Washington, DC, Armed Forces Institute of Pathology, 1997, pp 145-209

8. Solcia E, Capella C, Fiocca R, et al: Disorders of the endocrine system, in Ming SC, Goldman H (eds): Pathology of the Gastrointestinal Tract (ed 2). Baltimore, MD, Williams \& Wilkins, 1998, pp 295-322

9. La Rosa S, Uccella S, Capella C, et al: Localization of acidic fibroblast growth factor, fibroblast growth factor receptor-4, transforming growth factor- $\alpha$, and epidermal growth factor receptor in human endocrine cells of the gut and related tumors: An immunohistochemical study. Appl Immunohistochem 6:199-208, 1998

10. Rindi G, Azzoni C, La Rosa S, et al: ECL-cell tumor and poorly differentiated endocrine carcinoma of the stomach: Prognostic evaluation by pathological analysis. Gastroenterology 116:532-542, 1999

11. La Rosa S, Uccella S, Capella C, et al: Localization of hepatocyte growth factor and its receptor met in endocrine cells and related tumors of the gut and pancreas: An immunohistochemical study. Endocr Pathol 11:315-329, 2000

12. La Rosa S, Uccella S, Erba S, et al: Immunohistochemical detection of fibroblast growth factor receptors in normal endocrine cells and related tumors of the digestive system. Appl Immunohistochem Mol Morphol 9:319-328, 2001

13. Christofori G, Naik P, Hanahan D: Vascular endothelial growth factor and its receptors, flt-1 and flk-1, are expressed in normal pancreatic islets and throughout islet cell tumorigenesis. Mol Endocrinol 9:1760-1770, 1995

14. Kuroda M, Oka T, Oka Y, et al: Colocalization of vascular endothelial growth factor (vascular permeability factor) and insulin in pancreatic islet cells. J Clin Endocrinol Metab 80:3196-3200, 1995

15. Terris B, Scoazec Y, Rubbia L, et al: Expression of vascular endothelial growth factor in digestive neuroendocrine tumors. Histopathology 32:133-138, 1998

16. Decaussin M, Sartelet H, Robert C, et al: Expression of vascular endothelial growth factor (VEGF) and its two receptors (VEGF-R1-flt1 and VEGF-R2-flk1/KDR) in non-small cell lung carcinomas (NSCLCs): Correlation with angiogenesis and survival. J Pathol 188:369-377, 1999

17. Weidner N: Intratumor microvessel density as a prognostic factor in cancer. Am J Pathol 147:9-19, 1995

18. Bosari S, Lee AKC, DeLellis RA, et al: Microvessel quantitation and prognosis in invasive breast carcinoma. Hum PATHOL 23:755761,1992

19. Fan L, Iseki S: Immunohistochemical localization of vascular endothelial growth factor in the endocrine glands of the rat. Arch Histol Cytol 61:17-28, 1998

20. Seo Y, Baba H, Fukuda T, et al: High expression of vascular endothelial growth factor is associated with liver metastasis and poor prognosis for patients with ductal pancreatic adenocarcinoma. Cancer 88:2239-2245, 2000

21. Berse B, Brown LF, Water LVD, et al: Vascular permeability 
factor (vascular endothelial growth factor) gene is expressed differentially in normal tissues, macrophages, and tumors. Mol Biol Cell 3:211-220, 1992

22. Brown LF, Berse B, Jackman RW, et al: Expression of vascular permeability factor (vascular endothelial growth factor) and its receptors in adenocarcinomas of the gastrointestinal tract. Cancer Res 53:4727-4735, 1993

23. Shrifen JL, Doldi N, Ferrara N, et al: In the human fetus, vascular endothelial growth factor is expressed in epithelial cells and myocytes, but not vascular endothelium: Implications for mode of action. J Clin Endocrinol Metab 79:316-322, 1994

24. Rooman I, Schmit F, Bouwens L: Effect of vascular endothelial growth factor on growth and differentiation of pancreatic ductal epithelium. Lab Invest 76:225-232, 1997

25. Roberts WG, Palade GE: Neovasculature induced by vascular endothelial growth factor is fenestrated. Cancer Res 57:765-772, 1997

26. Bonner-Weir S: The microvasculature of the pancreas, with emphasis on that of the islets of Langerhans. Anatomy and functional aspects, in Go VLW, DiMagno EP, Gardner JD, et al (eds): The Pancreas: Biology, Pathobiology and Disease (ed 2). New York, NY, Raven, 1993, pp 759-768

27. Öberg C, Waltenberger J, Claesson-Welsh L, et al: Expression of protein kinases in islet cells: Possible role of the flk-1 receptor for $\beta$-cell maturation from duct cells. Growth Factor 10:115-126, 1994

28. Goto F, Goto K, Weindel K, et al: Synergistic effects of vascular endothelial growth factor and basic fibroblast growth factor on the proliferation and cord formation of bovine capillary endothelial cells within collagen gels. Lab Invest 69:508-517, 1993

29. Rofstad EK, Halsør EF: Vascular endothelial growth factor, interleukin-8, platelet-derived endothelial cell growth factor, and basic fibroblast growth factor promote angiogenesis and metastasis in human melanoma xenografts. Cancer Res 60:4932-4938, 2000

30. Xin X, Yang S, Ingle G, et al: Hepatocyte growth factor enhances vascular endothelial growth factor-induced angiogenesis in vitro and in vivo. Am J Pathol 158:1111-1120, 2001

31. Ahlman H, Wanberg B, Nilsson O: Growth regulation in carcinoid tumors. Endocrinol Metab Clin North Am 22:889-915, 1993

32. Yarden Y: Growth factor receptor tyrosine kinases. Ann Rey Biochem 57:443-478, 1988

33. Von Marchall Z, Cramer T, Höcker M, et al: De novo expression of vascular endothelial growth factor in human pancreatic cancer: Evident for an autocrine mitogenic loop. Gastroenterology 119:1358-1372, 2000

34. Fidler IJ: Critical factors in the biology of human cancer metastasis: Twenty-eighth G.H.A. Clowes memorial award lecture. Cancer Res 50:6130-6138, 1990

35. Bossi P, Viale G, Lee AKC, et al: Angiogenesis in colorectal tumors: Microvessel quantitation in adenomas and carcinomas with clinicopathological correlation. Cancer Res 55:5049-5053, 1995

36. Cioc AM, Perez-Montiel D, Ellison EC, et al: Correlation between microvascular density, histopathology, and outcome in neuroendocrine tumors of the pancreas. Mod Pathol 15:113A, 2002 